\title{
Impact of multicellular tumor spheroids as an in vivo-like tumor model on anticancer drug response
}

\author{
BIANCA GALATEANU $^{1 *}$, ARIANA HUDITA ${ }^{1 *}$, CAROLINA NEGREI $^{2}$, RODICA-MARIANA ION $^{3,4}$, \\ MARIETA COSTACHE ${ }^{1}$, MIRIANA STAN ${ }^{2}$, DRAGANA NIKITOVIC ${ }^{5}$, A. WALLACE HAYES ${ }^{6}$, \\ DEMETRIOS A. SPANDIDOS ${ }^{7}$, ARISTIDIS M. TSATSAKIS ${ }^{8}$ and OCTAV GINGHINA ${ }^{9}$
}

\author{
${ }^{1}$ Department of Biochemistry and Molecular Biology, University of Bucharest, Bucharest 050095; \\ ${ }^{2}$ Department of Toxicology, Faculty of Pharmacy, 'Carol Davila' University of Medicine and Pharmacy, \\ Bucharest 020956; ${ }^{3}$ National Institute of Research and Development for Chemistry and Petrochemistry - ICECHIM, \\ Bucharest 060021; ${ }^{4}$ Valahia University, Materials Engineering Department, Targoviste 130024, Romania; \\ ${ }^{5}$ Department of Anatomy-Histology-Embryology, Medical School, University of Crete, Heraklion 71003, Greece; \\ ${ }^{6}$ Michigan State University, East Lansing, MI 48824, USA; ${ }^{7}$ Laboratory of Clinical Virology, University of Crete \\ Medical School, Heraklion 71409; ${ }^{8}$ Department of Forensic Sciences and Toxicology, Medical School, University of Crete, \\ Heraklion 71003, Greece; ${ }^{9}$ Department of Surgery, ‘Sf. Ioan’ Emergency Clinical Hospital, \\ 'Carol Davila' University of Medicine and Pharmacy, Bucharest 042122, Romania
}

Received January 29, 2016; Accepted March 29, 2016

DOI: $10.3892 /$ ijo.2016.3467

\begin{abstract}
The incidence of colorectal cancer is higher in men than in women, amounting to $15 \%$ of cancer-related diseases as a whole. As such, undesirable effects, arising from the administration of current chemotherapeutic agents (the FOLFIRI/FOLFOX combinations), which are exerted on the remaining non-cancerous tissues and/or cells, have contributed to the occurrence of resistance to multiple drugs, thus markedly reducing their efficacy. However, the delivery of chemotherapeutic agents may be improved and their action may be more selectively targeted to diseased tissues/cells by means of developing biotechnologies and nano-techniques. Thus, the current focus is on creating biological tissue and related tumor models, by means of three-dimensional (3D) spheres, in an attempt to bridge the gap between results obtained in the pre-clinical phase and promising outcomes obtained in clinical trials. For this purpose, the characterization and use of so-called 'multicellular tumor spheroids', may prove to be invaluable. In this study, we focus on describing the efficacy of a model 3D system as compared to the traditional 2D tumor spheres in determining drug response, highlighting a potentially greater effect of the
\end{abstract}

Correspondence to: $\mathrm{Dr}$ Carolina Negrei, Department of Toxicology, Faculty of Pharmacy, 'Carol Davila' University of Medicine and Pharmacy, 6 Traian Vuia Street, Bucharest 020956, Romania

E-mail: carolina.negrei@outlook.com

*Contributed equally

Key words: colorectal cancer, liposomes, 5-fluorouracil, oxaliplatin, multicellular tumor spheroids, therapy drugs following the encapsulation of respective liposomes. The results obtained demonstrate the successful preparation of a suspension of liposomes loaded with folinic acid, oxaliplatin and 5-fluorouracil (5-FU), and loaded with meso-tetra (4-sulfonatophenyl) porphyrin. Following its use on HT-29 colorectal cancer cells, an important comparative reduction was noted in the viability of the HT-29 cells, demonstrating the efficacy of multicellular tumor spheroids carrying liposomes loaded with therapeutic drugs. These findings indicate that the method of drug encapsulation in liposomes may improve the treatment efficacy of chemotherapeutic agents.

\section{Introduction}

In total, $15 \%$ of the malignant diseases reported worldwide are colorectal cancer, translating into the second cause of cancer for women i.e., $9.4 \%$ of the total number of cases, and the third leading cause of cancer for men ( $10 \%$ of the total number of cases). The incidence rates are similar regardless of gender in patients with large bowel cancer (colon cancer), whereas the incidence rate is higher in men with rectal cancer. All things considered, in men, there is a higher overall occurrence of colorectal cancer than in women (1).

The increased survival for patients with colorectal cancer regardless of the disease stage has been significant and has remained constant over the past 60 years (2), with a marked relative improvement in the 5-year survival rate and in general survival depending on the level of access to health care and other socio-economic factors. These factors are responsible for the significant differences between regions and countries regarding the survival of patients with colorectal cancer (3-5).

An examination over the same time period has revealed the existence and inter-play of several risk factors leading to the development of colorectal cancer, among which are heredity, 
gender and age. In addition to such factors beyond our control, an increasing range of risk factors pertaining to the environment and personal lifestyle may also influence the occurrence of colorectal cancer.

Before the year 2000, the treatment for colorectal cancer mainly involved palliative chemotherapy, consisting of a combination of fluoropyrimidine-containing medicines [single-agent 5-fluorouracil (5-FU)] with folinic acid (FA). Treatment with 5 -FU led to a response rate of approximately $20 \%$ (tumor size decreased by approximately $50 \%$ in these patients). The survival rate in these patients is generally longer than that of patients who do not respond to fluorouracil. Thus, in patients with metastatic colorectal cancer, the 5-FU/FA treatment schedule led to a 4-month improvement in median survival (6).

The subsequent replacement of FA with oxaliplatin (OXP) in combination with 5-FU (FOLFOX) and irinotecan (FOLFIRI) provided a $20 \%$ increase in the global response rate (from 20-30 to 40-50\%), leading to a median overall survival of 12-20 months (7-10).

The efficacy of chemotherapy is substantially limited by side-effects on healthy cells and/or tissues, as well as the development of multidrug resistance. Such limitations may result from the lack of selectivity of chemotherapeutic agents to cancer cells, and may also be due to the fact that in order for sufficient and pharmacologically active concentrations of the drug to reach the target tissue, this often means contamination to the rest of the body (11). The prospect for the more efficient delivery of chemotherapeutic agents to selective cells/tissues may reside in various nano- and bio-technologies currently under development. Therefore, innovative nanosystems, such as liposomes, polymer nanoparticles and inorganic nanoparticles created to maximize the release of chemotherapeutic agents into the tumor tissue, and at the same time minimizing their accumulation and toxicity in the healthy tissue, offer encouraging new approaches that are being investigated and developed worldwide (12-14).

The lack of the selectivity of cytotoxic agents with regard to normal tissue and pathological tissue is a challenge in the context of developing a strategy for medicinal products and the treatment of tumors. In spite of the similar activity of the abovementioned therapies (FOLFOX/FOLFIRI) in the treatment of stage III colorectal cancer, their toxicity profile differs: the occurrence of alopecia and febrile neutropenia (for irinotecan, mostly) and polyneuropathy (for OXP) is often observed due to the need for long infusion periods (15).

Currently, much attention is being paid to the design of refined preclinical models that can bridge the gap between preclinical results and success in clinical trials. To help accelerate the translation of research into practice, three-dimensional (3D) spheroids for modeling cancer and tissue biology are being evaluated. Standard 2D cell cultures for examining the effects of anticancer agents are simple and convenient; however, they present significant limitations in reproducing the complexity and pathophysiology of tumor tissues in vivo (16-20).

To model solid tumors more accurately, several 3D culture systems have been developed: tissue explants, whole perfused organs, scaffold/microcarrier-based cultures and organotypic cultures (multicellular spheroids and cellular multilayers) $(17,18,21)$. Of these, the multicellular tumor spheroid (MCTS) model is the most well-characterized and the most widely used model. Tumor spheroids are heterogeneous cellular aggregates frequently characterized by hypoxic regions and necrotic centers $(22,23)$. MCTSs not only simulate the rough conditions in poorly vascularized tumors, but also enable the evaluation of compound penetration properties $(24,25,18)$.

Sutherland et al first applied this technique in cancer research in the 1970s (26). Since then, several methods have been used to obtain MCTSs: spontaneous aggregation (27,28), spinner flasks (29), rotary cell culture systems (17), poly-2-hydroxyethyl methacrylate (poly-Hema)-coated plates $(30,31)$, hanging drops (32), liquid overlay on agar (33-35), low binding plates $(36,37)$, gel/matrix-based culture (38) or polymeric scaffolds (39). Each method has advantages and limitations (17,39); however, no standardized and rapid protocols are currently available.

In the present study, using the example of human colorectal cancer, 3D spheroid models were generated and their impact on the response to clinically relevant drug combinations was evaluated. Herein, we report the impact of a 3D tumor sphere (MCTS) culture model on drug response as compared to a conventional $2 \mathrm{D}$ culture system and the potential enhancement of the effects of the drugs following their encapsulation into liposomes.

\section{Materials and methods}

Cell culture model. The HT-29 human colon adenocarcinoma cell line [obtained from the American Type Culture Collection (ATCC), Manassas, VA, USA] was employed in this study. The cells were cultured routinely as a monolayer in Dulbecco's modified Eagle's medium (DMEM), supplemented with $10 \%$ fetal bovine serum and $1 \%$ penicillin-streptomycin and incubated at $37^{\circ} \mathrm{C}$ under a humidified atmosphere of $5 \% \mathrm{CO}_{2}$. The cells were serially subcultured by trypsin treatment when they achieved $80 \%$ confluency and the medium was renewed 2-3 times/week.

All the biological experiments were performed in 2D monolayer culture and in MCTSs. The monolayers were obtained by seeding the cells in 96-well flat-bottom plates at an initial cell density of $2.5 \times 10^{4}$ cells $/ \mathrm{cm}^{2}$ and left 1 day prior incubation with the test compounds to allow attachment. The MCTSs were obtained at 4 days post-seeding of $5 \times 10^{3}$ cells/drop in 384-well Perfecta hanging drop culture plate (Fig. 1). The treatments were applied on the 5 th day of culture.

Drugs and treatments. To determine the $\mathrm{IC}_{50}$ value for 5-FU (code 1001963413; Sigma-Aldrich, St. Louis, MO, USA), OXP (code 1001946478; Sigma-Aldrich) and FA (code 101563489; Sigma-Aldrich) in the 2D culture system and in the MCTSs, several drug concentrations were screened (Table I).

The potential synergistic cytotoxic effects of the drugs were assessed by screening the combination of 5-FU and OXP with FA and the combination of all 3 drugs as described in Table II.

Furthermore, $5 \mathrm{mM} 5-\mathrm{FU}, 90 \mu \mathrm{M}$ OXP and $500 \mu \mathrm{M}$ FA were encapsulated into liposomes and the HT-29 cells in the $2 \mathrm{D}$ and $3 \mathrm{D}$ culture systems were treated with the resulting solutions for the screening of the cytotoxic effects.

Liposome synthesis and characterization. Liposomes were prepared by using the hydration-film method as described 


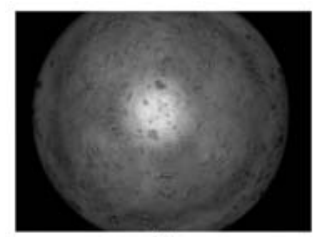

seeding

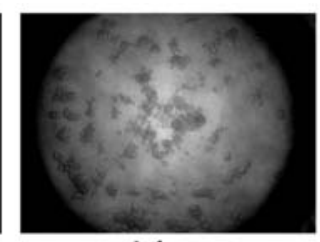

1 day

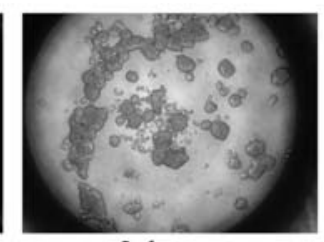

2 days

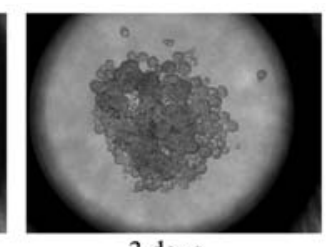

3 days

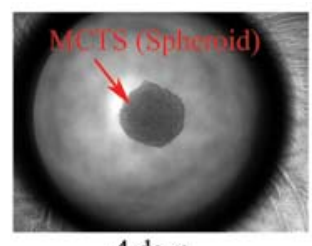

4 days

Figure 1. Multicellular tumor spheroid (MCTS) formation. contrast phase micrographs of HT-29 cells in the Perfecta Hanging drop culture system immediately after seeding and at 1,2,3 and 4 days of culture.

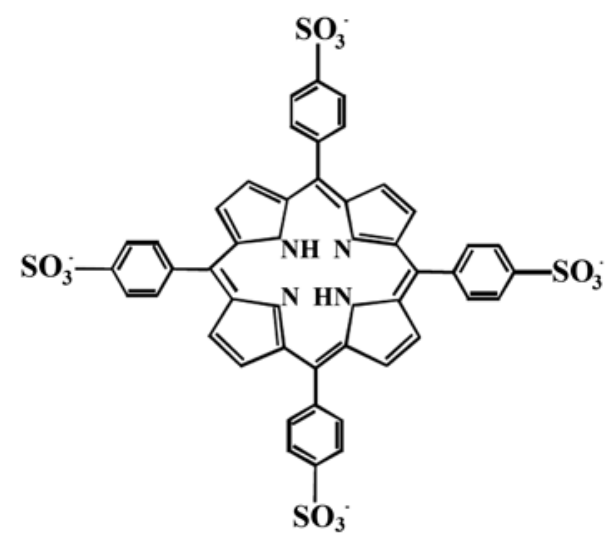

Figure 2. Chemical structure of meso-5,10,15,20-sulfonatophenyl porphyrin $\left(\mathrm{TPPS}_{4}\right)$.

in the study by [Derycke et al (40)]. The fluorescent marker, meso-tetra (4-sulfonatophenyl) porphyrin ( $\mathrm{TPPS}_{4}$ ) (Fig. 2), was synthesized and characterized as previously described in the study by [Ion et al (41)].

Briefly, $1 \mathrm{mg}$ of TPPS $_{4}(1.2 \mu \mathrm{mol})$ and $7.4 \mathrm{mg}$ dipalmitoylphosphatidylcholine (DPPC) $(9.4 \mu \mathrm{mol})$ with a 10:100 ratio of porphyrin/DPPC were dissolved in $10 \mathrm{ml}$ chloroform. Following the evaporation of the solvent, the thin lipid film was hydrated with $10 \mathrm{ml}$ of phosphate buffer $(\mathrm{pH}$ 7.6) in a water bath at $30-40^{\circ} \mathrm{C}$. The resulting suspension was then sonicated for $90 \mathrm{~min}$ at or slightly above the phase transition temperature which is $42^{\circ} \mathrm{C}$ for DPPC. Small unilamellar vesicles (SUVs) were prepared by sonication (US). The final phospholipid concentration was approximately $15 \mathrm{mM}$. Porphyrin was added to the liposomes at room temperature (approximately $22^{\circ} \mathrm{C}$ ).

Drug-loaded liposomes were prepared as described above in $5 \mathrm{mM} 5$-FU, $90 \mu \mathrm{M}$ OXP and $500 \mu \mathrm{M}$ FA solutions. The particle sizes and the zeta potential of the liposomes were evaluated by dynamic light scattering (DLS) using a Zetasizer instrument and a computer with Zetasizer software (from Malvern Instruments Ltd., Malvern, UK) (Fig. 3).

Additionally, light optical microscopy (LOM) was used for the stratigraphic characterization of polychrome surfaces using a Leica DM 1000 stereomicroscope and a Leica EC3 camera (Leica, Mannheim, Germany), under a magnification of x40-x600 (Fig. 4).

\section{Cytotoxicity assay}

MTT spectrophotometric assay. In order to assess the toxicity of 5-FU, OXP and FA on the HT-29 cells, an MTT assay was performed. Briefly, both the monolayers and the MCTSs were
Table I. Drugs concentrations screened for the assessment of $\mathrm{IC}_{50}$ values on HT- 29 cancer cells.

\begin{tabular}{lcl}
\hline Culture system & Drugs & Screened concentrations \\
\hline 2D monolayer & 5-FU & $5 \mathrm{mM}, 500 \mu \mathrm{M}, 250 \mu \mathrm{M}$, \\
& & $125 \mu \mathrm{M}, 62.5 \mu \mathrm{M}, 1.25 \mu \mathrm{M}$ \\
& OXP & $200 \mu \mathrm{M}, 90 \mu \mathrm{M}, 50 \mu \mathrm{M}$, \\
& & $25 \mu \mathrm{M}, 12.5 \mu \mathrm{M}, 2.5 \mu \mathrm{M}$ \\
& FA & $1 \mathrm{mM}, 500 \mu \mathrm{M}, 250 \mu \mathrm{M}$, \\
& & $125 \mu \mathrm{M}, 62.5 \mu \mathrm{M}, 1.25 \mu \mathrm{M}$ \\
MCTSs & 5-FU & $5 \mathrm{mM}, 10 \mathrm{mM}, 15 \mathrm{mM}$ \\
& OXP & $90 \mu \mathrm{M}, 300 \mu \mathrm{M}, 500 \mu \mathrm{M}$ \\
& FA & $500 \mu \mathrm{M}, 1.5 \mathrm{mM}, 2 \mathrm{mM}$ \\
\hline
\end{tabular}

2D, two-dimensional; OXP, oxaliplatin; FA, folinic acid; 5-FU, 5-fluorouracil; MCTSs, multicellular tumor spheroids.

Table II. Drug concentrations screened for the assessment of their potential synergistic cytotoxic effects on HT-29 cancer cells.

\begin{tabular}{ll}
$\begin{array}{l}\text { Culture } \\
\text { system }\end{array}$ & \multicolumn{1}{c}{$\begin{array}{c}\text { Screened drugs combinations and } \\
\text { their respective concentrations }\end{array}$} \\
\hline 2D monolayer & $\begin{array}{l}5 \mathrm{mM} 5-\mathrm{FU}+500 \mu \mathrm{M} \mathrm{FA} \\
90 \mu \mathrm{M} \mathrm{OXP}+500 \mu \mathrm{M} \mathrm{FA}\end{array}$ \\
& $5 \mathrm{mM} 5-\mathrm{FU}+90 \mu \mathrm{M} \mathrm{OXP}+500 \mu \mathrm{M} \mathrm{FA}$ \\
MCTSs & $15 \mathrm{mM} 5-\mathrm{FU}+2 \mathrm{mM} \mathrm{FA}$ \\
& $500 \mu \mathrm{M} \mathrm{OXP}+2 \mathrm{mM} \mathrm{FA}$ \\
& $15 \mathrm{mM} 5-\mathrm{FU}+500 \mu \mathrm{M} \mathrm{OXP}+2 \mathrm{mM} \mathrm{FA}$ \\
\hline
\end{tabular}

2D, two-dimensional; MCTSs, multicellular tumor spheroids; OXP, oxaliplatin; FA, folinic acid; 5-FU, 5-fluorouracil.

prepared as described above in triplicate. The culture medium was then removed and the cells were treated with various concentrations of the drugs (Table I). Following $24 \mathrm{~h}$ of exposure to the drugs, the HT-29 cells in monolayers were incubated for $1 \mathrm{~h}$ with $1 \mathrm{mg} / \mathrm{ml}$ MTT solution and the HT-29 cells in the MCTSs were incubated for $2 \mathrm{~h}$ with $5 \mathrm{mg} / \mathrm{ml}$ MTT solution, allowing metabolically active cells to form formazan crystals, which were further solubilized in DMSO. The concentration of the resultant solutions was spectrophotometrically quantified at $550 \mathrm{~nm}$ using a multimode reader (Appliskan; Thermo Fisher Scientific, Waltham, MA, USA). 
In order to evaluate the potential synergistic toxic effects of the drugs on the cancer cells, HT-29 cell viability was assessed following exposure of the cells to different combinations of the test compounds (Table II) by the MTT assay as described above. The only difference was that the treatment regimen was designed using the $\mathrm{IC}_{50}$ value of each compound in different combinations.

To examine the increase in drug uptake by the cells, the toxicity of the drug-loaded liposomes was assessed after $24 \mathrm{~h}$ of treatment by evaluating the HT-29 cell viability using the same MTT assay.

DAPI staining of the HT-29 cells nuclei. In order to evaluate the dimension of the MCTSs with or without treatment, HT-29 cell nuclei were stained with 4',6-diamidino-2-phenylindole (DAPI). In this view, untreated MCTSs and those treated with 5-FU, OXP, FA, 5-FU + FA and 5-FU + OXP + FA for $24 \mathrm{~h}$ were fixed with cold methanol. After $20 \mathrm{~min}$ at $40^{\circ} \mathrm{C}$, all the MCTSs were washed in PBS buffer and then incubated in $2 \mu \mathrm{g} / \mu \mathrm{l}$ DAPI solution for $10 \mathrm{~min}$ at room temperature. Images were captured using a Leica CytoVision Microscope (Leica).

Liveldead fluorescence microscopy assay. The morphology of the HT-29 3D MCTSs and the diffusion potential of the drugs were investigated by the simultaneous fluorescent labeling of both living and dead cells using the Live/dead kit (Invitrogen Life Technologies, Foster, CA, USA). HT-29 spheroids were stained for $20 \mathrm{~min}$ in the dark using a calcein AM and ethidium bromide mixture prepared according to the manufacturer's instructions. Images were captured using an Olympus IX71 microscope with CellF software (Olympus, Hamburg, Germany).

Statistical analysis. The spectrophotometric data obtained were statistically analyzed using GraphPad Prism 3.03 software, one-way ANOVA and the Bonferroni test. All the experiments were performed with 3 biological replicates and each data set is presented as the average of 3 replicates (mean \pm standard deviation). A value of $\mathrm{P}<0.05$ was considered to indicate a statistically significant difference.

\section{Results}

Our results demonstrated that the 5-FU, OXP and FA drug-loaded and the TPPS4-loaded liposome suspensions were successfully prepared for further testing on the HT-29 cells (Figs. 3 and 4).

Cytotoxicity screening of the testcompounds on the HT-29 cells. The viability of the HT-29 cells in the 2D and 3D culture systems exposed to various concentrations of 5-FU, OXP and FA, was determined by MTT spectrophotometric assay following $24 \mathrm{~h}$ of treatment. The quantitative data were statistical analyzed and the $\mathrm{IC}_{50}$ values were determined for 5-FU, OXP and FA. The results for both the 2D system and MCTSs are graphically represented in Fig. 5.

Our results demonstrated that all the test compounds decreased the viability of the HT-29 cells in a concentration-dependent manner in both culture systems. Following treatment with all the test compounds (5-FU, OXP and FA) at the higher concentrations, the viability of the HT-29 cells decreased significantly within $24 \mathrm{~h}$ compared with the

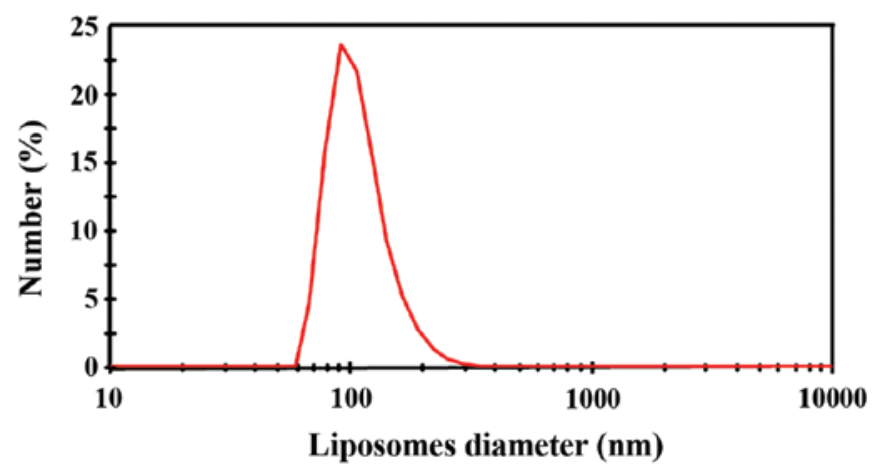

Figure 3. Liposome size distributions of liposomes measured by dynamic light scattering.
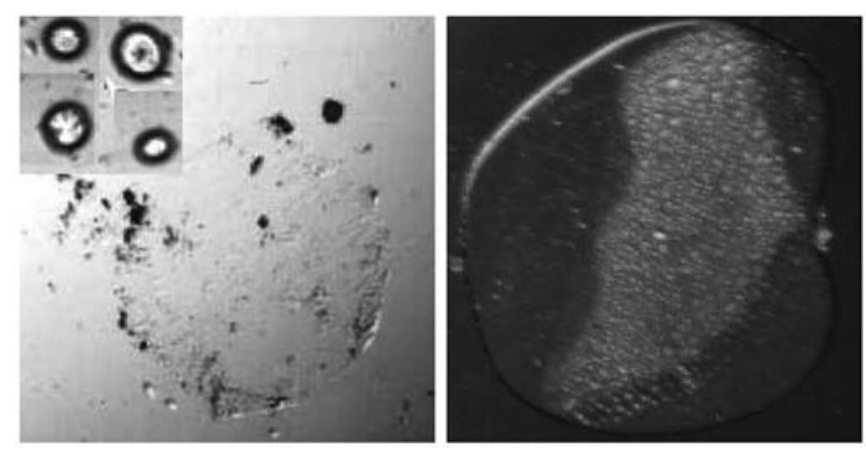

Figure 4. Light optical microscopy images of meso-5,10,15,20-sulfonatophenyl porphyrin $\left(\mathrm{TPPS}_{4}\right.$ ) unloaded liposomes (left panel) and $\mathrm{TPPS}_{4}$-loaded liposomes (right panel).

untreated HT-29 cells (control), revealing the clear cytotoxic potential of these anticancer drugs. Furthermore, the $\mathrm{IC}_{50}$ value of each compound was determined. A 50\% decrease in HT-29 cell viability was observed in the $2 \mathrm{D}$ culture system following exposure to $5 \mathrm{mM} 5-\mathrm{FU}, 90 \mu \mathrm{M}$ OXP and $500 \mu \mathrm{M}$ FA. By contrast, in the HT-29 MCTSs, the same treatments resulted in a decrease in cell viability of 8.52, 9.17 and $9.2 \%$, respectively. Consequently, the $\mathrm{IC}_{50}$ values determined in the $3 \mathrm{D}$ system for 5-FU, OXP and FA were significantly higher than those obtained in monolayer cultures (15 mM 5-FU, $500 \mu \mathrm{M}$ OXP and $2 \mathrm{mM} \mathrm{FA}$ ).

MCTS imagistic evaluation. The MCTSs were subsequently subjected to imagistic evaluations following $24 \mathrm{~h}$ of treatment with the test compounds at the determined $\mathrm{IC}_{50}$ values. The images presented in Fig. 6 were captured following the fluorescent labeling of the HT-29 nuclei with DAPI.

As revealed by the image of the untreated MCTSs, compact multicellular spheroids were obtained. Furthermore, apart from FA, all treatment with all the test drugs decreased the spheroid dimensions, possibly due to their cytotoxic effects on the peripheral HT-29 cells. Of note, the spheroids treated with OXP and 5-FU + OXP + FA did not display a smooth contour following $24 \mathrm{~h}$ of treatment and subsequently, their round shape was markedly altered by the treatments.

Additionally, a second image evaluation was employed following the fluorescent labeling of both living and dead cells 

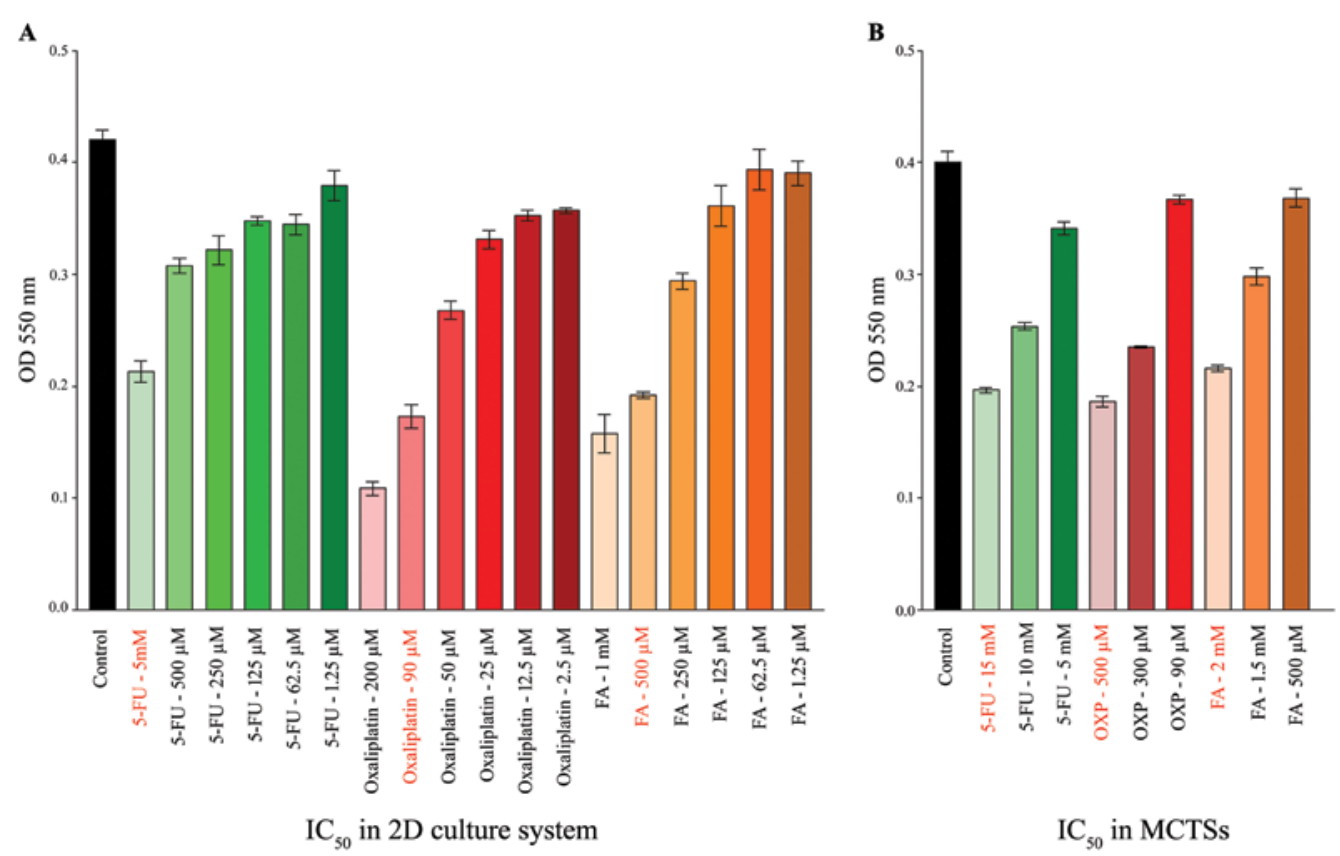

Figure 5. Viability of HT-29 cells in the (A) two-dimensional (2D) system and (B) multicellular tumor spheroids (MCTSs) exposed to various concentrations of 5-fluorouracil (5-FU), oxaliplatin (OXP) and folinic acid (FA) as evaluated by MTT assay following $24 \mathrm{~h}$ of incubation. OD, optical density.
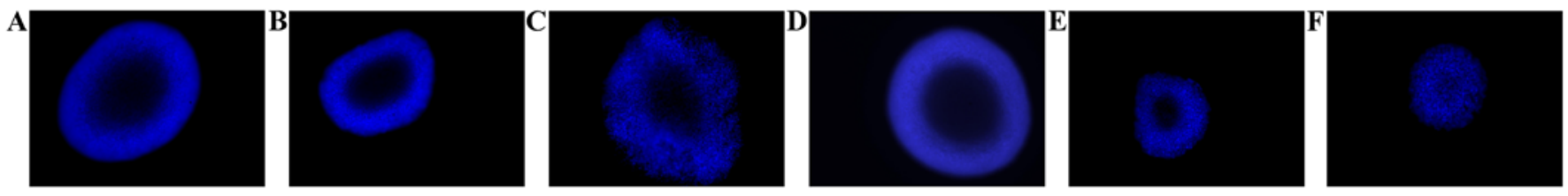

Figure 6. Fluorescence microscopy images of HT-29 cells. DAPI-stained nuclei in (A) untreated multicellular tumor spheroids (MCTSs) and in MCTSs treated for $24 \mathrm{~h}$ with (B) 5-fluorouracil (5-FU), (C) oxaliplatin (OXP), (D) folinic acid (FA), (E) 5-FU + FA and (F) 5-FU + OXP + FA.

with calcein AM and ethidium bromide, respectively. Images were then captured using an Olympus IX71 microscope with CellF software (Fig. 7).

Fluorescence images revealed the overall morphology of the MCTSs. The cell density in the core of the untreated spheroid was found low, but no dead cells were identified. By contrast, a large number of dead cells was observed in all the treated spheroids, possibly due to the diffusion of the drugs and high levels of cellular stress inside the 3D structure. Additionally, a significantly higher amount of dead cells was observed in the MCTSs treated with combinations of the drugs as compared to single drug treatment.

Enhanced cytotoxicity evaluation of combinations of the test compounds on HT-29 cells. The cytotoxicity of $5 \mathrm{mM} 5-\mathrm{FU}+500 \mu \mathrm{M} \mathrm{FA}, 90 \mu \mathrm{M} \mathrm{OXP}+500 \mu \mathrm{M} \mathrm{FA}$ and $5 \mathrm{mM} 5-\mathrm{FU}+90 \mu \mathrm{M}$ OXP $+500 \mu \mathrm{M}$ FA on HT-29 monolayer cells was examined by MTT assay. The same investigation was performed on the MCTS model using $15 \mathrm{mM} 5-\mathrm{FU}+2 \mathrm{mM}$ FA, $500 \mu \mathrm{M} \mathrm{OXP}+2 \mathrm{mM}$ FA and $15 \mathrm{mM} 5-\mathrm{FU}+500 \mu \mathrm{M}$ OXP $+2 \mathrm{mM}$ FA treatments. The quantitative data obtained were statistically analyzed and graphically represented (Fig. 8) using GraphPad Prism software.

As shown in Fig. 8, following 24 h of incubation with combinations of the drugs, the viability of the HT-29 cells decreased significantly as compared to the untreated controls $(\mathrm{P}<0.0001)$ in both culture systems. In the monolayer cultures, cell viability decreased by $63.14 \%$ following treatment with $5-\mathrm{FU}+\mathrm{FA}$, by $47 \%$ with OXP + FA and by $>75 \%$ following treatment with 5-FU + OXP + FA. Following the same pattern, in the MCTSs, cell viability decreased by $59 \%$ following treatment with $5-\mathrm{FU}+\mathrm{FA}$, by $48 \%$ with OXP + FA and by $>75 \%$ following treatment with 5-FU + OXP + FA. These results indicated that the combination of OXP and FA did not provide additional benefits, whereas the combination of 5-FU with FA and all 3 drugs together resulted in a significant decrease in cell viability both in the $2 \mathrm{D}$ and $3 \mathrm{D}$ culture systems.

Effect of liposome-encapsulated drugs on HT-29 cells. To investigate the potential increase in cellular uptake in MCTSs, 5-FU, OXP and FA were encapsulated in fluorescently labeled liposomes. The HT-29 3D MCTSs were then treated for $24 \mathrm{~h}$ with a solution containing all 3 drug-loaded liposomes in a final concentration corresponding to the $2 \mathrm{D} \mathrm{IC}_{50}$ value for each drug (5 mM 5-FU, $90 \mu \mathrm{M}$ OXP and $500 \mu \mathrm{M}$ FA liposome loaded). Cell viability was assessed by MTT spectrophotometric assay and the data were analyzed and graphically represented using GraphPad Prism software (Fig. 9).

Our data revealed a significant decrease $(\mathrm{p}<0.01)$ in the viability of the HT-29 MCTSs treated with the drug-loaded 


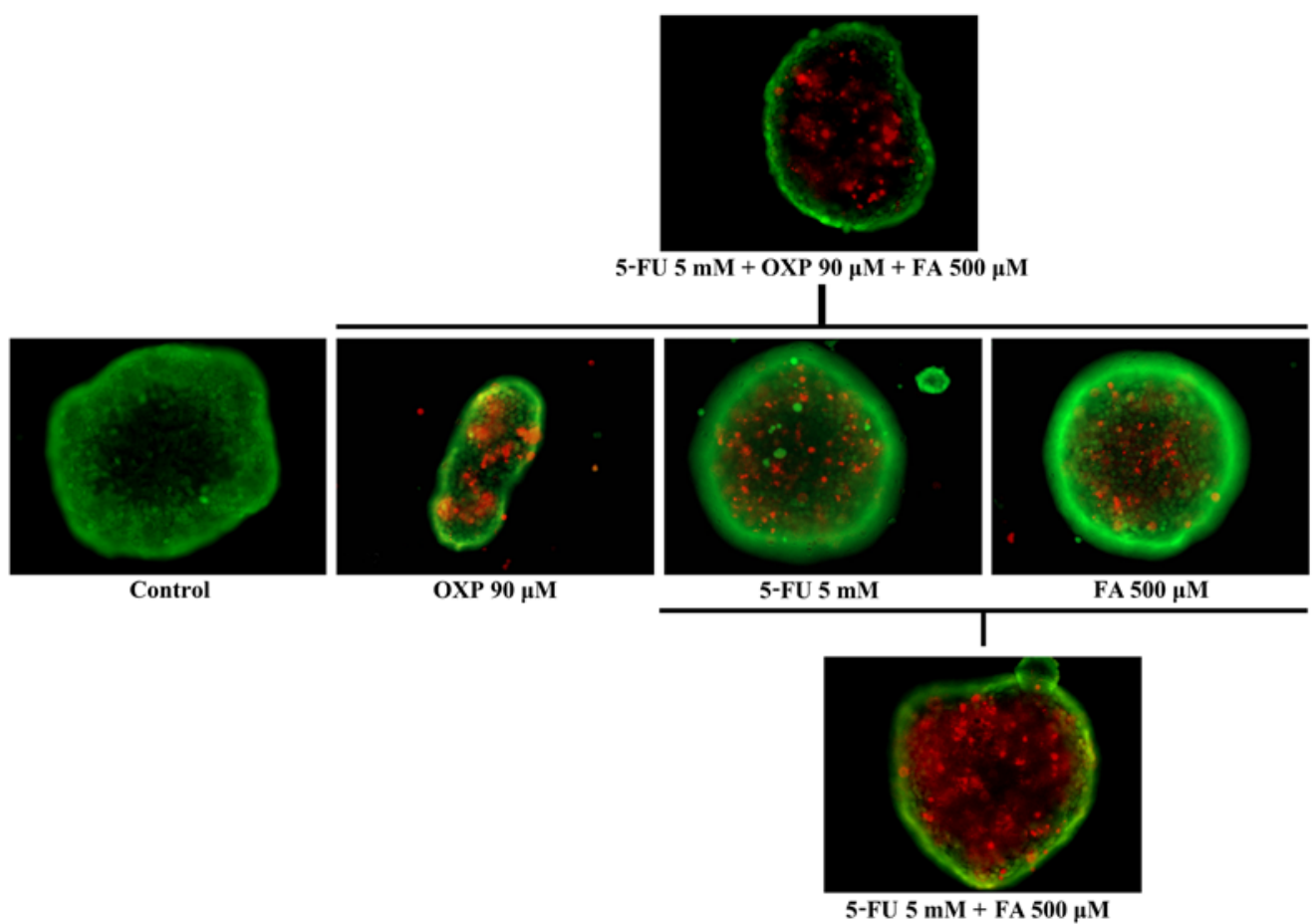

Figure 7. Fluorescence microscopy micrographs showing untreated HT-29 multicellular tumor spheroids (MCTS) and HT-29 MCTSs 24 h exposed to 5-fluorouracil (5-FU), oxaliplatin (OXP), folinic acid (FA) and their combinations (green fluorescence, live cells; red fluorescence, dead cells).
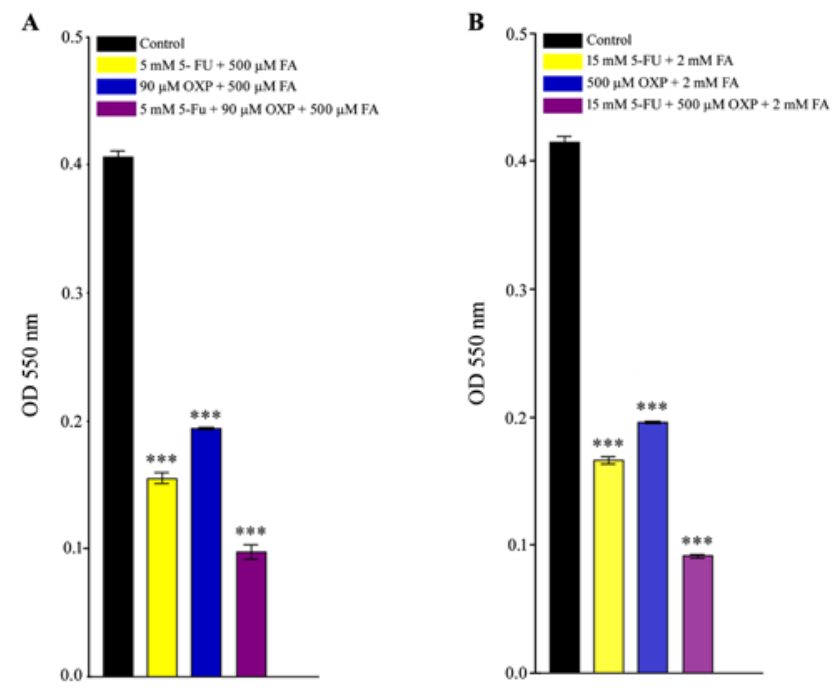

Figure 8 . HT-29 cell viability following $24 \mathrm{~h}$ of treatment with 5-fluorouracil (5-FU) + folinic acid (FA), oxaliplatin (OXP) + FA and 5-FU + OXP + FA in (A) $2 \mathrm{D}$ culture system and in (B) multicellular tumor spheroids as revealed by MTT spectrophotometric assay. OD, optical density. ${ }^{* * *} \mathrm{p}<0.0001$, treated cells vs. untreated cells.

liposomes as compared to the untreated cells, while treatment with the unloaded liposomes did not lead to a significant decrease. These results suggest that the encapsulation of the drugs in liposomes enhances the treatment efficacy.

\section{Discussion}

There is an increasing interest in using 3D spheroids for modeling cancer and tissue biology in order to accelerate the

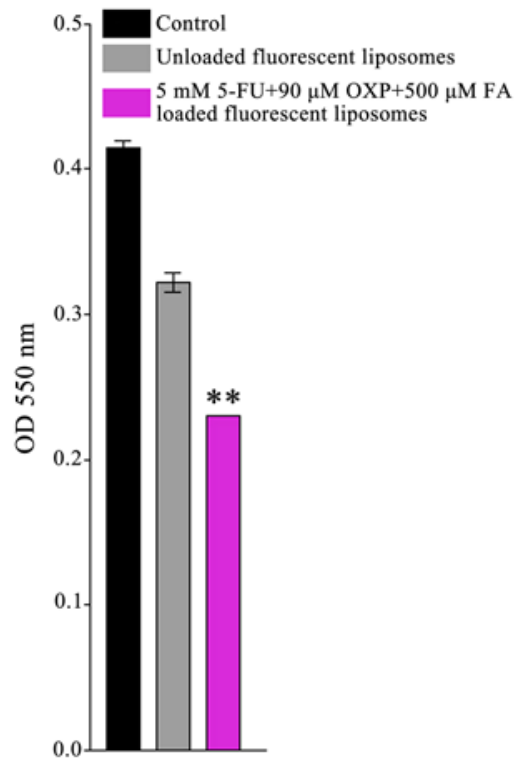

Figure 9. HT-29 cell viability in multicellular tumor spheroid structures following $24 \mathrm{~h}$ of treatment with unloaded liposomes, 5-fluorouracil (5-FU), oxaliplatin (OXP) and folinic acid (FA) drug-loaded liposomes as revealed by MTT spectrophotometric assay. OD, optical density. ${ }^{* *} \mathrm{p}<0.01$, 5-FU + OXP + FA-loaded liposomes vs. untreated cells.

translation of research into clinicl practice. MCTSs have been used as surrogates of tiny tumors for studying distribution and determining the efficacy of chemo- and radiotherapeutic agents (42-44). In this study, we demonstrated concentration-response effects of different readouts and measured the $\mathrm{IC}_{50}$ values of the drugs, and compared the results obtained from 3D spheroid to those of 2D HT-29 monolayer cell cultures. 
Spheroids mimic tumor behavior more effectively than conventional 2D culture systems as spheroids, similar to tumors, contain both surface-exposed and deeply buried cells, well-oxygenated and hypoxic cells, and proliferating and non-proliferating cells. Three phases of spheroidal growth can generally be distinguished: firstly, all the spheroid cells are proliferating as characterized by exponential growth. Secondly, a change in cell cycle distribution occurs with an increasing accumulation of non-proliferating cells in central regions of the spheroids. Thus, there is a progressive reduction in the proliferating fraction of cells and a linear increase in the spheroid diameter with time during the second growth phase (45). Consequently, a multicellular tumor spheroid is composed of proliferating, quiescent and necrotic cells. Cells located at the periphery of the spheroid are actively proliferating, whereas those located in the center are necrotic. Spheroids are known to be intrinsically more resistant to anticancer drugs compared to the same cells grown as monolayer cell cultures (46).

The heterogeneity of some drug uptake might be responsible for the observed resistance of spheroids to different treatment methods. Consequently, $\mathrm{TPPS}_{4}$ and drug-loaded liposomes were synthetized and characterized in order to improve the drug administration method and to increase the sensitivity of the HT-29 cells in the MCTSs to the treatment. 3D microtumors of HT-29 colorectal adenocarcinoma cells were achieved after 4 days post-seeding in Perfecta hanging drop culture system plates. Furthermore, following the screening of several concentrations, both in monolayer cultures and in MCTSs, the $\mathrm{IC}_{50}$ values of 5-FU, OXP and FA were determined. Our data demonstrated that the viability of the HT-29 cells decreased by $50 \%$ following treatment with $5 \mathrm{mM} 5-\mathrm{FU}, 90 \mu \mathrm{M}$ OXP and $500 \mu \mathrm{M} \mathrm{FA}$, whereas in the 3D culture system, the same decrease was observed following treatment with $15 \mathrm{mM} 5$-FU, $500 \mu \mathrm{M}$ OXP and $2 \mathrm{mM}$ FA. These results indicate that the concentrations used in the MCTSs to kill half of the cell population were much higher than in those used in the monolayer culture system, confirming that 3D microtumors are much more resistant to treatment than the same cells in monolayer. Consequently, we strongly recommend that the 3D model be considered for relevant studies on cancer biology.

The combination of the test drugs (5-FU, OXP and FA) at their respective $\mathrm{IC}_{50}$ concentrations in both culture systems led to a decrease in cellular viability of $>50 \%$, suggesting a potential synergistic effect. Consequently, the combination of these 3 drugs may enable dosage adjustments in the view of decreasing the concentration of each drug without altering the the response of the cells to treatment.

Lastly, but not least, treatment with 5-FU, OXP and FA at $\mathrm{IC}_{50}$ values corresponding to those used in the $2 \mathrm{D}$ culture system decreased the viability of the HT-29 cells in the $3 \mathrm{D}$ culture systems by $50 \%$ following their encapsulation into liposomes. These results suggest that drug uptake by the cells in MCTSs was significantly increased following their encapsulation into liposomes, which may lead to an increase in their biodisponibility in vivo and subsequently, allow a lower treatment dosage.

Consequently, as expected, the 3D cultures exhibited a greater resistance to the anticancer drugs than the $2 \mathrm{D}$ cultures. This was possibly due to the dimension of the MCTSs, with cell-cell and cell-matrix contact, which improves the viability of the system. Particularly, with regard to drug resistance, the 3D system blocks the diffusion of the drug to all the cells, as the cells on the outer layers of the spheroid provide a natural barrier. Furthermore, the gradation of oxygen within the spheroid provides a hypoxic core similar to the hypoxic regions within solid tumors. Therefore, the hypoxic core of the spheroids should be able to modulate the cells, in such a manner that they are able to resist the drug effects and thus exhibit greater viability.

In conclusion, the present study demonstrates the efficacy of multicellular tumor spheroids carrying liposomes loaded with therapeutic drugs. However, further in vivo studies are warranted in order to confirm the dosage adjustments when using combinations of these 3 drugs (5-FU, OXP and FA) and their ensuing encapsulation into liposomes.

\section{References}

1. Zavoral M, Suchanek S, Zavada F, Dusek L, Muzik J, Seifert B and Fric P: Colorectal cancer screening in Europe. World J Gastroenterol 15: 5907-5915, 2009.

2. Jemal A, Clegg LX, Ward E, Ries LA, Wu X, Jamison PM, Wingo PA, Howe HL, Anderson RN and Edwards BK: Annual report to the nation on the status of cancer, 1975-2001, with a special feature regarding survival. Cancer 101: 3-27, 2004.

3. Boyle $P$ and Langman JS: ABC of colorectal cancer: Epidemiology. BMJ 321: 805-808, 2000.

4. Parkin DM, Bray F, Ferlay J and Pisani P: Global cancer statistics, 2002. CA Cancer J Clin 55: 74-108, 2005.

5. Jackson-Thompson J, Ahmed F, German RR, Lai SM and Friedman C: Descriptive epidemiology of colorectal cancer in the United States, 1998-2001. Cancer 107 (Suppl 5): 1103-1111, 2006.

6. Mayer RJ: Moving beyond fluorouracil for colorectal cancer. N Engl J Med 343: 963-964, 2000.

7. Saltz LB, Cox JV, Blanke C, Rosen LS, Fehrenbacher L, Moore MJ, Maroun JA, Ackland SP, Locker PK, Pirotta N, et al; Irinotecan Study Group: Irinotecan plus fluorouracil and leucovorin for metastatic colorectal cancer. N Engl J Med 343: 905-914, 2000

8. de Gramont A, Figer A, Seymour M, Homerin M, Hmissi A, Cassidy J, Boni C, Cortes-Funes H, Cervantes A, Freyer G, et al: Leucovorin and fluorouracil with or without oxaliplatin as first-line treatment in advanced colorectal cancer. J Clin Oncol 18: 2938-2947, 2000.

9. Giacchetti S, Perpoint B, Zidani R, Le Bail N, Faggiuolo R, Focan C, Chollet P, Llory JF, Letourneau Y, Coudert B, et al: Phase III multicenter randomized trial of oxaliplatin added to chronomodulated fluorouracil-leucovorin as first-line treatment of metastatic colorectal cancer. J Clin Oncol 18: 136-147, 2000.

10. Scheithauer W, Rosen H, Kornek GV, Sebesta C and Depisch D: Randomised comparison of combination chemotherapy plus supportive care with supportive care alone in patients with metastatic colorectal cancer. BMJ 306: 752-755, 1993.

11. Mimeault M, Hauke R and Batra SK: Recent advances on the molecular mechanisms involved in the drug resistance of cancer cells and novel targeting therapies. Clin Pharmacol Ther 83: 673-691, 2008.

12. Flaten GE, Dhanikula AB, Luthman K and Brandl M: Drug permeability across a phospholipid vesicle based barrier: a novel approach for studying passive diffusion. Eur J Pharm Sci 27: 80-90, 2006.

13. Goldberg RM, Sargent DJ, Morton RF, Fuchs CS, Ramanathan RK, Williamson SK, Findlay BP, Pitot HC and Alberts SR: A randomized controlled trial of fluorouracil plus leucovorin, irinotecan, and oxaliplatin combinations in patients with previously untreated metastatic colorectal cancer. J Clin Oncol 22: 23-30, 2004.

14. Dinu-Pîrvu C, Ferdes M, Buţu A, Orţan A and Ghica MV: Physicochemical investigation of low soluble biocompounds entrapped in lipid carriers. Farmacia 61: 182-192, 2013.

15. House MG, Ito H, Gönen M, Fong Y, Allen PJ, DeMatteo RP, Brennan MF, Blumgart LH, Jarnagin WR, D'Angelica MI: Survival after hepatic resection for metastatic colorectal cancer: trends in outcomes for 1,600 patients during two decades at a single institution. J Am Coll Surg 210: 744-752, 752-755, 2010. 
16. Abbott A: Cell culture: Biology's new dimension. Nature 424: 870-872, 2003.

17. Mazzoleni G, Di Lorenzo D and Steimberg N: Modelling tissues in 3D: The next future of pharmaco-toxicology and food research? Genes Nutr 4: 13-22, 2009.

18. Pampaloni F, Reynaud EG and Stelzer EH: The third dimension bridges the gap between cell culture and live tissue. Nat Rev Mol Cell Biol 8: 839-845, 2007.

19. Ghosh S, Spagnoli GC, Martin I, Ploegert S, Demougin P, Heberer $M$ and Reschner A: Three-dimensional culture of melanoma cells profoundly affects gene expression profile: A high density oligonucleotide array study. J Cell Physiol 204: 522-531, 2005

20. Ernst A, Hofmann S, Ahmadi R, Becker N, Korshunov A, Engel F, Hartmann C, Felsberg J, Sabel M, Peterziel H, et al: Genomic and expression profiling of glioblastoma stem cell-like spheroid cultures identifies novel tumor-relevant genes associated with survival. Clin Cancer Res 15: 6541-6550, 2009.

21. Haycock JW: 3D cell culture: A review of current approaches and techniques. Methods Mol Biol 695: 1-15, 2011.

22. Sutherland RM, Sordat B, Bamat J, Gabbert H, Bourrat B and Mueller-Klieser W: Oxygenation and differentiation in multicellular spheroids of human colon carcinoma. Cancer Res 46: 5320-5329, 1986

23. Hirschhaeuser F, Menne H, Dittfeld C, West J, Mueller-Klieser W and Kunz-Schughart LA: Multicellular tumor spheroids: An underestimated tool is catching up again. J Biotechnol 148: 3-15, 2010.

24. Spencer VA, Xu R and Bissell MJ: Gene expression in the third dimension: The ECM-nucleus connection. J Mammary Gland Biol Neoplasia 15: 65-71, 2010.

25. Jacks $\mathrm{T}$ and Weinberg RA: Taking the study of cancer cell survival to a new dimension. Cell 111: 923-925, 2002

26. Sutherland RM, McCredie JA and Inch WR: Growth of multicell spheroids in tissue culture as a model of nodular carcinomas. J Natl Cancer Inst 46: 113-120, 1971.

27. Singh SK, Clarke ID, Terasaki M, Bonn VE, Hawkins C, Squire J and Dirks PB: Identification of a cancer stem cell in human brain tumors. Cancer Res 63: 5821-5828, 2003.

28. Deisboeck TS, Berens ME, Kansal AR, Torquato S, Stemmer-Rachamimov AO and Chiocca EA: Pattern of self-organization in tumour systems: Complex growth dynamics in a novel brain tumour spheroid model. Cell Prolif 34: 115-134, 2001.

29. Wartenberg M, Dönmez F, Ling FC, Acker H, Hescheler J and Sauer H: Tumor-induced angiogenesis studied in confrontation cultures of multicellular tumor spheroids and embryoid bodies grown from pluripotent embryonic stem cells. FASEB J 15: 995-1005, 2001

30. Xiang X, Phung Y, Feng M, Nagashima K, Zhang J, Broaddus VC, Hassan R, Fitzgerald D and Ho M: The development and characterization of a human mesothelioma in vitro $3 \mathrm{D}$ model to investigate immunotoxin therapy. PLoS One 6: e14640, 2011.

31. Del Duca D, Werbowetski T and Del Maestro RF: Spheroid preparation from hanging drops: Characterization of a model of brain tumor invasion. J Neurooncol 67: 295-303, 2004.
32. Friedrich J, Seidel C, Ebner R and Kunz-Schughart LA: Spheroid-based drug screen: Considerations and practical approach. Nat Protoc 4: 309-324, 2009.

33. Weiswald LB, Guinebretière JM, Richon S, Bellet D, Saubaméa B and Dangles-Marie V: In situ protein expression in tumour spheres: Development of an immunostaining protocol for confocal microscopy. BMC Cancer 10: 106, 2010.

34. Li Q, Chen C, Kapadia A, Zhou Q, Harper MK, Schaack J and LaBarbera DV: 3D models of epithelial-mesenchymal transition in breast cancer metastasis: High-throughput screening assay development, validation, and pilot screen. J Biomol Screen 16: 141-154, 2011.

35. Wright MH, Calcagno AM, Salcido CD, Carlson MD, Ambudkar SV and Varticovski L: Brcal breast tumors contain distinct CD44+/CD24- and CD133+ cells with cancer stem cell characteristics. Breast Cancer Res 10: R10, 2008.

36. Takaishi S, Okumura T, Tu S, Wang SS, Shibata W, Vigneshwaran R, Gordon SA, Shimada Y and Wang TC: Identification of gastric cancer stem cells using the cell surface marker CD44. Stem Cells 27: 1006-1020, 2009.

37. Lee GY, Kenny PA, Lee EH and Bissell MJ: Three-dimensional culture models of normal and malignant breast epithelial cells. Nat Methods 4: 359-365, 2007.

38. Fischbach C, Chen R, Matsumoto T, Schmelzle T, Brugge JS, Polverini PJ and Mooney DJ: Engineering tumors with 3D scaffolds. Nat Methods 4: 855-860, 2007.

39. Kim JB, Stein R and O'Hare MJ: Three-dimensional in vitro tissue culture models of breast cancer - a review. Breast Cancer Res Treat 85: 281-291, 2004.

40. Derycke AS and De Witte PA: Transferrin-mediated targeting of hypericin embedded in sterically stabilized PEG-liposomes. Int J Oncol 20: 181-187, 2002.

41. Ion RM and Apostol S: Photochemical study of porphyrin aggregates. Rev Chem 56: 607-620, 2005.

42. Mueller-Klieser W: Multicellular spheroids: A review on cellular aggregates in cancer research. J Cancer Res Clin Oncol 113: 101-122, 1987.

43. Wibe E, Berg JP, Tveit KM,Nesland JM and Lunde S: Multicellular spheroids grown directly from human tumour material. Int $\mathbf{J}$ Cancer 34: 21-26, 1984.

44. Boothby CD, Daniel J, Adam S and Dyson JE: Use of a laser diffraction particle sizer for the measurement of mean diameter of multicellular tumour spheroids. In Vitro Cell Dev Biology 25: 946-950, 1989.

45. Olive PL and Durand RE: Drug and radiation resistance in spheroids: cell contact and kinetics. Cancer Metastasis Rev 13: 121-138, 1994.

46. Inoue T, Inoue T, Teshima T, Murayama S, Shimizutani K, Fuchihata $\mathrm{H}$ and Furukawa S: Phase III trial of high and low dose rate interstitial radiotherapy for early oral tongue cancer. Int $\mathbf{J}$ Radiat Oncol Biol Phys 36: 1201-1204, 1996. 